\title{
E3 ubiquitin ligase isolated by differential display regulates cervical cancer growth in vitro and in vivo via microRNA-143
}

\author{
JIBIN LI $^{1}$, XINLING WANG ${ }^{1}$, YANSHANG ZHANG ${ }^{1}$ and YAN ZHANG ${ }^{2}$ \\ ${ }^{1}$ Department of Obstetrics and Gynecology, Hebei General Hospital, Shijiazhuang, Hebei 050051; \\ ${ }^{2}$ Department of Orthopedics, Gongli Hospital of Pudong New Area, Shanghai 200135, P.R. China
}

Received June 9, 2015; Accepted January 19, 2016

DOI: $10.3892 /$ etm.2016.3429

\begin{abstract}
Cervical cancer is one of the most common gynecological cancers worldwide. Aberrant expression of E3 ubiquitin ligase isolated by differential display (EDD) has been detected in various types of tumor and has been demonstrated to have an important role in carcinogenesis, tumor growth and drug resistance. However, the role of EDD in cervical cancer and its underlying molecular mechanisms remains unknown. The present study aimed to investigate the role of EDD in the tumorigenicity of cervical cancer. EDD expression levels were measured using reverse transcription-quantitative polymerase chain reaction and western blotting in SiHa, HeLa, CaSki, c-41 and c-33A cervical cancer cell lines and cervical cancer tissue specimens. A functional study was performed using cell proliferation, colony formation, cell apoptosis assays in vitro and tumor growth assays in vivo with EDD either overexpressed or silenced. In the present study, EDD expression levels were significantly upregulated in cervical cancer cell lines and tissue samples. EDD knockdown significantly inhibited colony formation, cell proliferation and tumor growth and accelerated cell apoptosis in the cervical cancer cell lines and tissue samples. Furthermore, microRNA (miR)-143 expression levels were low in cervical cancer tissue samples and were negatively correlated with EDD expression. miR-143 silencing eliminated the effect of EDD on cell proliferation, colony formation and cell apoptosis in the cervical cancer cells, which suggested that miR-143 is critical for EDD-mediated regulation of cervical cancer cell growth. The results of the present study indicated that EDD may promote cervical cancer growth in vivo and in vitro by targeting miR-143. In conclusion, EDD may have an oncogenic role in cervical cancer and may serve as a potential therapeutic target for the treatment of patients with cervical cancer.
\end{abstract}

Correspondence to: Dr Yan Zhang, Department of Orthopedics, Gongli Hospital of Pudong New Area, 219 Miaopu Road, Shanghai 200135, P.R. China

E-mail: cath_yan@163.com

Key words: apoptosis, cervical cancer, E3 ubiquitin ligase isolated by differential display, microRNA-143, tumor growth

\section{Introduction}

Cervical cancer is the most common type of gynecological cancer worldwide, accounting for $\sim 8 \%$ of all female malignancies, second only to breast cancer $(1,2)$. Every year, cervical cancer affects $\sim 500,000$ women worldwide, $\sim 250,000$ of which succumb to the disease (3). Although cervical cancer screening has been popularized globally $(4,5)$, large numbers of patients with advanced cervical cancer remain (6). Notably, hh $\sim 85 \%$ of novel cases and $80 \%$ of fatal cases of cervical cancer occur in developing countries $(7,8)$. Human papillomavirus (HPV) is known to be the most common etiological agent of cervical cancer, and $99 \%$ of cervical cancer cases are attributed to human HPV infection $(9,10)$. However, HPV infection alone is not sufficient for the malignant transformation of cervical epithelial cells. Various cofactors and molecular events are required in order to promote the pathogenic process of cervical cancer $(11,12)$; therefore, early detection and treatment of precancerous lesions is particularly important in order to prevent the progression of cervical cancer. The molecular pathogenesis of cervical cancer remains poorly understood. Investigating the molecular mechanisms underlying the development of cervical cancer, searching for novel molecular markers for early diagnosis and developing effective therapeutic targets is urgently required.

E3 ubiquitin ligase isolated by differential display (EDD) is a human ortholog of the Drosophila melanogaster hyperplastic discs gene (hyd) $(13,14)$, which was initially isolated as a progestin-regulated gene in human T47D breast cancer cells $(14,15)$. Ubiquitin ligase E3 is able to identify degraded proteins and to conduct ubiquitin tagging of the substrate. Ubiquitin-mediated protein degradation is associated with various important protein signaling pathways, including transcription, cell cycle and DNA damage (16-20). Previous studies have demonstrated that EDD participates in the regulation of cyclin levels and cell cycle progression (21-24), regulates ubiquitination and the degradation of protein phosphatase (25), and has a role in transcriptional regulation and the response to DNA damage (15,26-30). Furthermore, it has previously been demonstrated that EDD is ectopically overexpressed in certain types of cancer and has an important role in cancer cell growth, tumorigenesis and drug resistance (31-36). However the effects of EDD on the occurrence and progression of cervical cancer and its associated molecular mechanisms have yet to be fully elucidated. 
MicroRNAs (miRNAs or miRs) are a class of non-coding small RNAs of 20-24 nucleotides in length that regulate gene and protein expression (37). miRNAs participate in a diverse range of biological processes including development, proliferation, differentiation, apoptosis and disease (38-43). Furthermore, certain miRNAs have been demonstrated to function as oncogenes or tumor suppressors, therefore they are directly involved in human cancer, including liver, lung, breast, colon and brain cancer (44-53). The miRNA expression profiles of cervical cancer cells and tissues have previously been analyzed using cDNA cloning (52). The results indicated that aberrant expression of oncogenic and tumor suppressive miRNAs was required for cancer cell growth in cervical cancer, and miR-143 and miR-145 were demonstrated to be the tumor suppressive miRNAs. Furthermore, it was subsequently demonstrated that miR-143 is capable of inhibiting tumor growth and angiogenesis, inducing cancer cell apoptosis and cell cycle arrest, increasing chemosensitivity, and regulating cyclooxygenase stability and expression in colorectal, lung and pancreatic cancer $(44,46,50,54)$. These results suggested that miR-143 had an important role in the carcinogenic process.

The present study aimed to investigate the role of EDD in the tumorigenicity of cervical cancer, and to further elucidate the underlying molecular mechanism, in order to improve the understanding of the pathogenesis of cervical cancer and to aid in the development of novel therapeutics for the disease.

\section{Materials and methods}

Tissue samples and cell lines. Human cervical cancer tissue samples $(n=39)$ and normal cervical tissue samples $(n=13)$ were obtained from patients at the Hebei General Hospital (Shijiazhuang, China). The 39 patients with cervical cancer were aged between 27 and 55 years (average age, 46 years) and had an average weight of $54 \mathrm{~kg}$ (weight range, 48 to $63 \mathrm{~kg}$ ). All patients in this group had been diagnosed with stage IA-IVB cervical cancer, according to the FIGO staging system (55). The 13 normal control patients were aged between 30 and 55 years and weighed between 48 and $61 \mathrm{~kg}$. The control patients were undergoing a simple hysterectomy at the Hebei General Hospital due to uterine leiomyomata. All cancer specimens used in the analyses consisted of $>90 \%$ tumor cells, as examined by a gynecologic pathologist. Cancer specimens from patients with concomitant gynecological problems were excluded from the study. Informed consent was obtained from all patients prior to the surgical procedure, and approval was obtained from the Medical Ethics Committee of the Hebei General Hospital.

Normal cervical epithelial cells and five cervical cancer cell lines, including SiHa, HeLa, CaSki, c-41 and c-33A, were purchased from the American Type Culture Collection (Manassas, VA, USA). Cell culture was conducted according to methods previously described by Liu et al (56). Briefly, the cells were cultured in RPMI 1640 medium supplemented with $10 \%$ fetal bovine serum (FBS; both purchased from Invitrogen; Thermo Fisher Scientific, Inc., Waltham, MA, USA), $2 \mathrm{mM}$ L-glutamine, $100 \mu \mathrm{g} / \mathrm{ml}$ streptomycin and $100 \mathrm{U} / \mathrm{ml}$ penicillin (all obtained from Gibco; Thermo Fisher Scientific, Inc.). The cells were incubated at $37^{\circ} \mathrm{C}$, in an atmosphere containing $5 \% \mathrm{CO}_{2}$.
Cell proliferation, apoptosis and colony formation assays. SiHa cells $\left(1 \times 10^{4}\right.$ cells $\left./ \mathrm{ml}\right)$ were seeded onto 96 -well plates, after which cell proliferation and apoptosis were assessed using the MTT Cell Proliferation/Viability Assay kit (cat. no. 11465007001; Sigma-Aldrich Chemie Gmbh, Munich, Germany) and the Annexin-V-FITC Apoptosis Detection kit (cat. no. APOAF-20TST; Sigma-Aldrich Chemie Gmbh) with a flow cytometer (BD FACSCalibur ${ }^{\mathrm{TM}}$; BD Biosciences, Franklin Lakes, NJ, USA), respectively, according to the manufacturer's protocols. Subsequently, SiHa cells $\left(1 \times 10^{4}\right)$ were suspended in $1.5 \mathrm{ml}$ complete medium [consisting of RPMI 1640 (Invitrogen; Thermo Fisher Scientific, Inc.) supplemented with $10 \%$ fetal bovine serum (FBS; GE Healthcare Life Sciences, Logan, UT, USA)] containing $0.45 \%$ low melting point agarose (Invitrogen; Thermo Fisher Scientific, Inc.) and then seeded into $35 \mathrm{~mm}$ tissue culture plates containing $1.5 \mathrm{ml}$ complete medium and $0.75 \%$ agarose on the bottom layer, which were then incubated for 10 days at $37^{\circ} \mathrm{C}$. The plates were then stained with $0.005 \%$ crystal violet for $30 \mathrm{sec}$ (Sigma-Aldrich Chemie Gmbh) and the SiHa cell colonies $(>0.5 \mathrm{~mm}$ in diameter) were counted under a microscope (Leica DMI3000; Leica Microsystems GmbH, Wetzlar, Germany), according to a previous study (57).

Cell transfection. In order to analyze the effects of EDD overexpression or knockdown, $\mathrm{SiHa}$ cells $\left(1 \times 10^{4}\right)$ were transfected with adenovirus-expressing Ad-EDD or retrovirus expressing short hairpin (Sh)-EDD, respectively. Ad-EDD/Ad-negative control (NC) and Sh-EDD/Sh-NC were designed and synthesized by Invitrogen (Thermo Fisher Scientific, Inc.). For miR-143 silencing, SiHa cells $\left(1 \times 10^{4}\right)$ were transfected with the pLL3.7 lentivirus vector (Addgene, Cambridge, MA, USA) encoding a miR-143 inhibitor sponge. The miR-143 inhibitor sponge was synthesized by GenePharma (Shanghai, China). The cells were cultured in six-well plates to $70-80 \%$ confluency and transfected using Lipofectamine 2000 (Invitrogen; Thermo Fisher Scientific, Inc.). The cells were harvested $48 \mathrm{~h}$ post-transfection for reverse transcription-quantitative polymerase chain reaction (RT-qPCR) in order to determine the transfection efficiency.

Tumor xenograft experiments. Xenograft mice experiments were performed as previously described (56). Briefly, SiHa cells $\left(5 \times 10^{6}\right)$ transfected with Sh-NC, Sh-EDD, Ad-NC or Ad-EDD were injected subcutaneously into the flanks of female athymic nude mice (age, 3-4 weeks; n=6/group), purchased from Shanghai Laboratory Animal Co., Ltd. (Shanghai, China). The mice were maintained under at $21-22^{\circ} \mathrm{C}$ under a 12 -h light/dark cycle. To obtain the tumors, the mice were sacrificed by an overdose of pentobarbital $(50 \mathrm{mg} / \mathrm{kg}$; Sigma-Aldrich Chemie Gmbh) 4 weeks following inoculation.

$R T$-qPCR analysis. Total RNA (100 ng) was extracted from the harvested tissue samples and cell lines using TRIzol ${ }^{\circledR}$ reagent (Invitrogen; Thermo Fisher Scientific, Inc.) and was purified using RNase-Free DNase Set (Qiagen,Inc., Valencia,CA,USA), according to the manufacturer's protocols. Subsequently, $5 \mathrm{ng}$ RNA was reverse transcribed into cDNA using SuperScript III Reverse Transcriptase (Invitrogen; Thermo Fisher Scientific, Inc.). qPCR was performed using TaqMan MicroRNA Assays 
$\mathbf{A}$

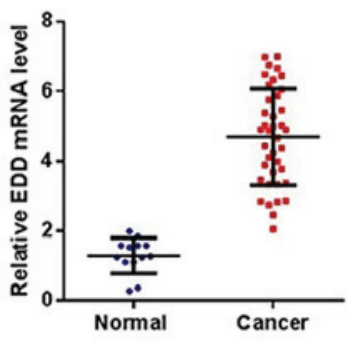

B

Normal

EDD

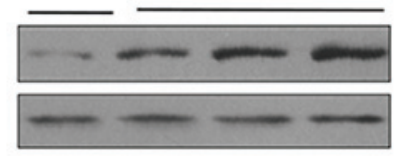

GAPDH

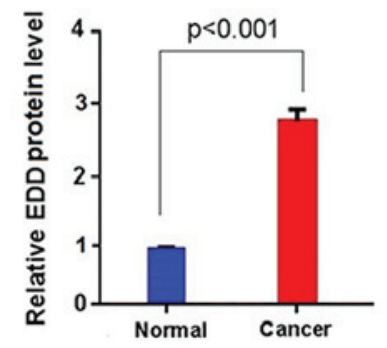

C

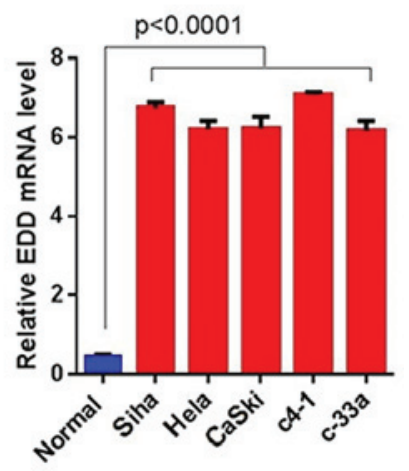

Figure 1. EDD expression levels are upregulated in cervical cancer tissue samples and cell lines. (A) The mRNA expression levels of EDD are upregulated in cervical cancer tissue samples ( $\mathrm{n}=13$ in normal group, $\mathrm{n}=39$ in cancer group). (B) The protein expression levels of EDD are upregulated in cervical cancer tissue samples ( $n=2$ in normal group, $n=5$ in cancer group). (C) The mRNA expression levels of EDD are upregulated in the cervical cancer cell lines ( $n=3$ in each group). EDD, E3 ubiquitin ligase isolated by differential display.

A
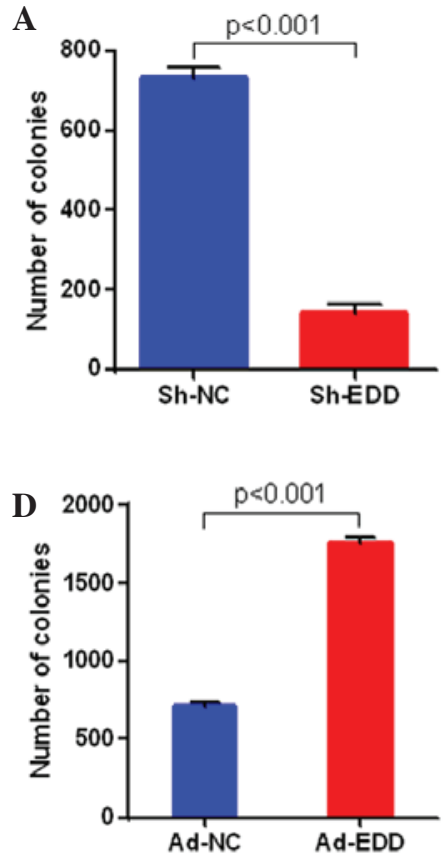

B
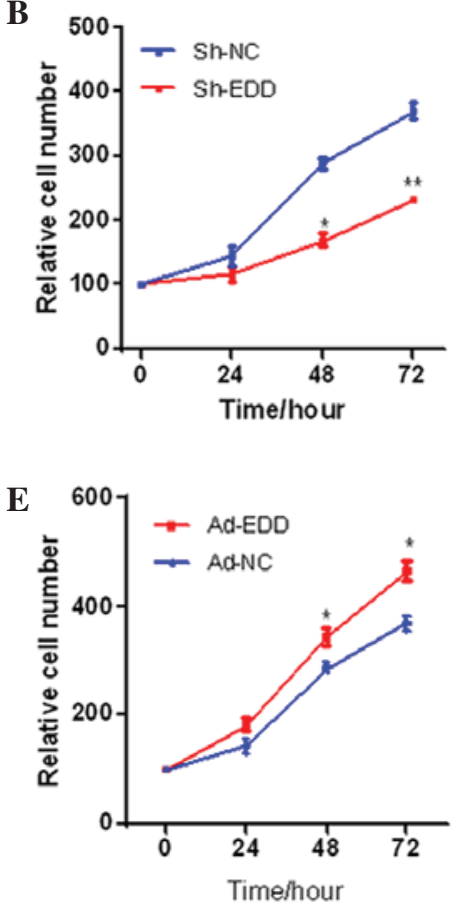

C

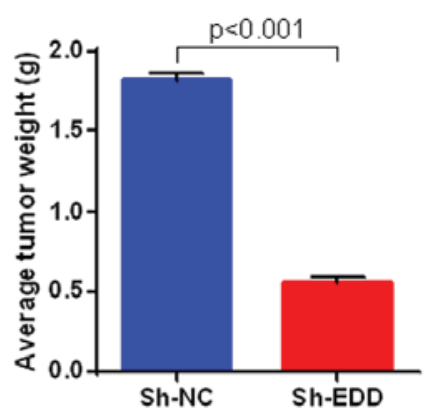

F

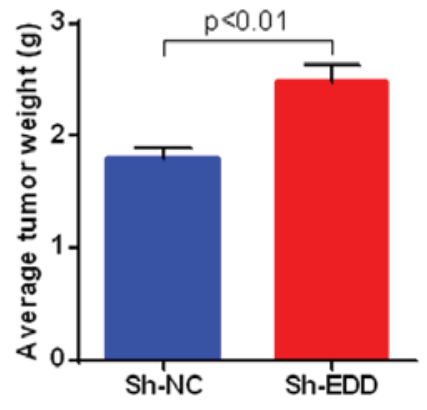

Figure 2. EDD promoted cervical cancer growth in vitro and in vivo. SiHa cervical cancer cells were infected with retrovirus expressing Sh-NC or Sh-EDD and adenovirus expressing control green fluorescent protein (Ad-NC) and Ad-EDD. (A) EDD knockdown inhibited the colony formation of SiHa cells (n=3 in each group). (B) EDD knockdown inhibited cell proliferation of SiHa cells. ${ }^{*} \mathrm{P}<0.05$ and ${ }^{* *} \mathrm{P}<0.01$, vs. sh-NC. (C) EDD knockdown inhibited tumor growth ( $\mathrm{n}=3$ in each group). (D) EDD overexpression promoted the colony formation of SiHa cells ( $\mathrm{n}=3$ in each group). (E) EDD overexpression promoted the cell proliferation of SiHa cells. "P<0.05, vs. ad-NC. (F) EDD overexpression promoted tumor growth ( $\mathrm{n}=3$ in each group). EDD, E3 ubiquitin ligase isolated by differential display; Sh-NC, short hairpin negative control; Sh-EDD, short hairpin EDD.

(Thermo Fisher Scientific, Inc.) on an ABI 7300 Real-Time PCR System (Applied Biosystems; Thermo Fisher Scientific, Inc.), according to a previous study (44). The primer sequences were as follows: EDD forward, 5'-TTAGGCTTTTGGTAA ATGGCTGCG-3' and reverse, 5'-TGAGGGCATAGGCTG GAATCCTTC-3'; miR-143 forward, 5'-AGTGCGTGTCGT GGAGTC-3' and reverse, 5'-GCCTGAGATGAAGCACTG T-3'; and $\beta$-actin forward, 5'-CATCCTGCGTCTGGACCT-3' and reverse, 5'-CAGGAGGAGCAATGATCTTG-3'. $\beta$-actin was used as the internal control. EDD, miR-143 and $\beta$-actin primers were designed as previously described by Liu et al (54) and Clancy et al (30). The PCR cycling conditions were as follows: Pre-heating at $95^{\circ} \mathrm{C}$ for $5 \mathrm{~min}$, followed by 35 cycles of denaturation for $30 \mathrm{sec}$ at $95^{\circ} \mathrm{C}$, annealing for $1 \mathrm{~min}$ at $55^{\circ} \mathrm{C}$ and extension for $1 \mathrm{~min}$ at $72^{\circ} \mathrm{C}$, with a final extension for $5 \mathrm{~min}$ at $72^{\circ} \mathrm{C}$. Relative gene expression levels were calculated using the $2^{-\Delta \Delta \mathrm{Cq}}$ method (58).

Western blotting. Western blotting was performed as previously described by Zhang et al (44). Briefly, total protein $(50 \mu \mathrm{g})$ 
A

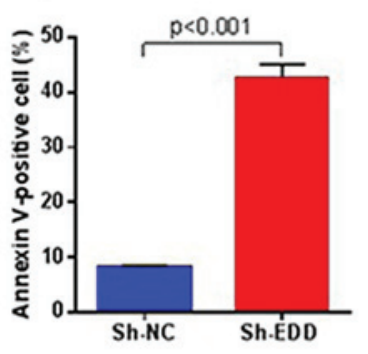

B

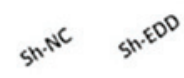

Bcl-2

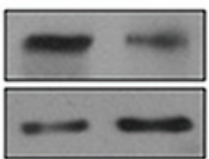

Pro-caspase 3

Active-caspase 3

GAPDH
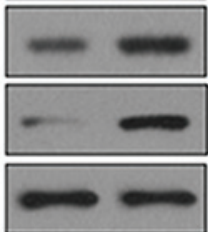

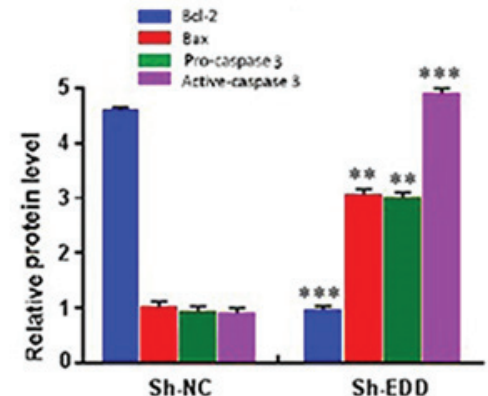

Sh.NC

Sh.EDD

Figure 3. EDD knockdown induces cervical cancer cell apoptosis. SiHa cells were infected with retrovirus expressing Sh-NC or Sh-EDD for 48 h, and fluorescence-activated cell sorting analysis was performed on the cells. The proteins of the SiHa cells were extracted for western blot analysis. (A) EDD knockdown induced the apoptosis of cervical cancer cells ( $\mathrm{n}=3$ in each group). (B) EDD knockdown induced the downregulation of anti-apototic protein Bcl-2 expression, and the upregulation of pro-apoptotic Bax and active-caspase 3 expression. ${ }^{* *} \mathrm{P}<0.01$ and ${ }^{* * * *} \mathrm{P}<0.001$, vs. sh-NC. EDD, E3 ubiquitin ligase isolated by differential display; Bcl-2, B cell lymphoma 2; Bax, Bcl-2-associated X protein; Sh-NC, short hairpin negative control; Sh-EDD, short hairpin EDD.
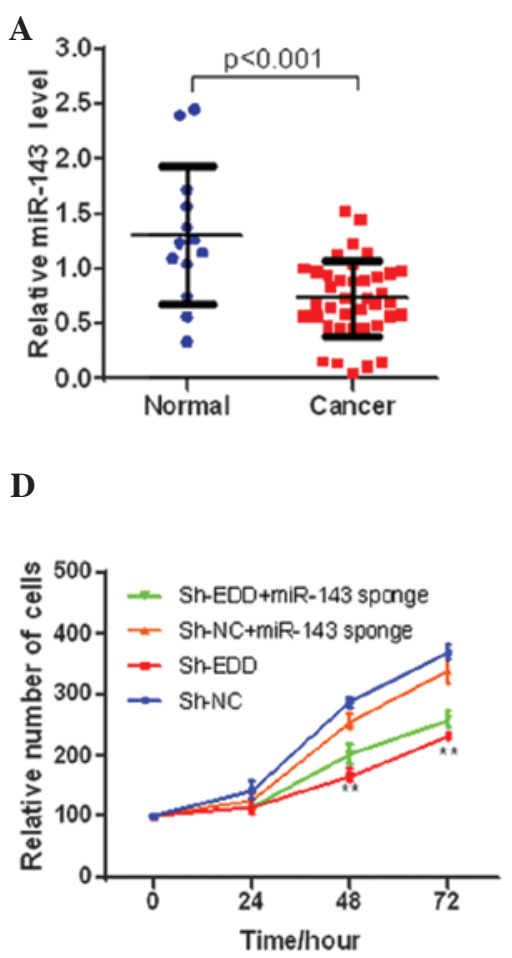

B

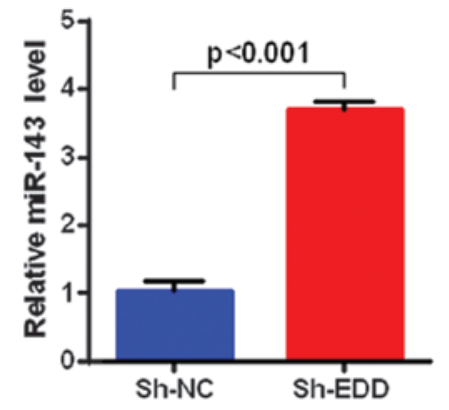

$\mathbf{E}$

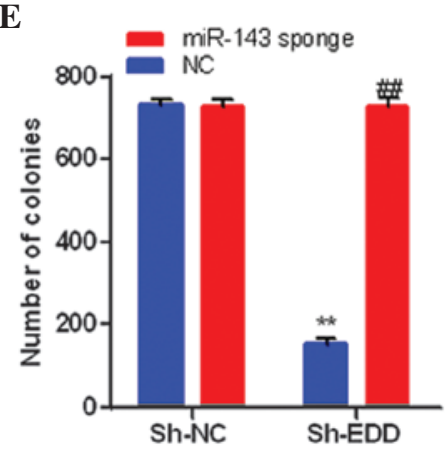

C

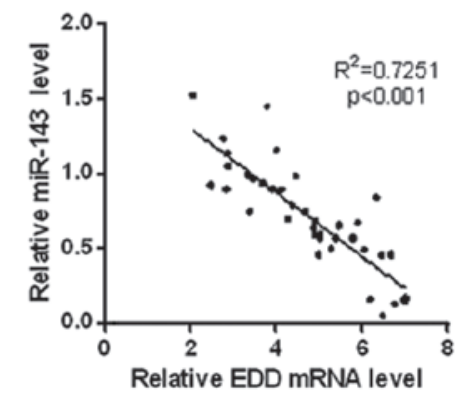

F

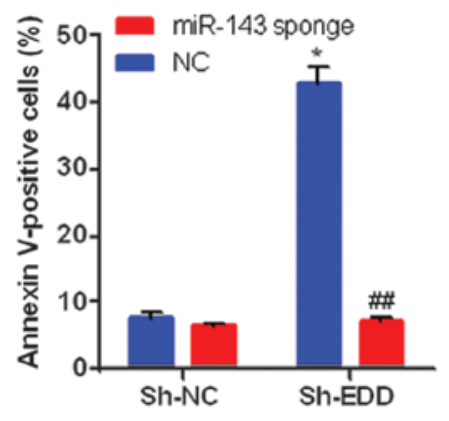

Figure 4. EDD regulates cervical cancer cell growth through miR-143. (A) The expression levels of miR-143 are downregulated in cervical cancer tissue samples ( $\mathrm{n}=13$ in normal group, $\mathrm{n}=39$ in cancer group). (B) EDD knockdown increases miR-143 expression levels in SiHa cells ( $\mathrm{n}=3$ in each group). (C) The expression of miR-143 was negatively correlated with the expression of EDD in cervical cancer tissue samples (n=39). (D) miR-143 silencing partly reversed the inhibition effect on cell proliferation caused by EDD knockdown in SiHa cells. ${ }^{* *} \mathrm{P}<0.01$, vs. sh-NC. (E) miR-143 silencing eliminated the effect on colony formation caused by EDD knockdown in SiHa cells ( $\mathrm{n}=3$ in each group). ${ }^{* *} \mathrm{P}<0.01$, vs. sh-NC $+\mathrm{NC} ;{ }^{\# \#} \mathrm{P}<0.01$, vs. sh-EDD $+\mathrm{NC}$. (F) miR-143 silencing prevented the apoptosis caused by EDD knockdown in SiHa cells ( $\mathrm{n}=3$ in each group). $\mathrm{P}<0.05$, vs. sh-NC $+\mathrm{NC}$; ${ }^{\# \#} \mathrm{P}<0.01$, vs. sh-EDD $+\mathrm{NC}$. EDD, E3 ubiquitin ligase isolated by differential display; Sh-NC, short hairpin negative control; Sh-EDD, short hairpin EDD; miR, microRNA.

was extracted from the tissue samples and $\mathrm{SiHa}$ cell line using lysis buffer (20 mM Tris-HCl, pH 7.4, 2 mM EDTA, $25 \mathrm{mM}$ 2-mercaptoethanol,0.5 mM AEBSF, $0.5 \%$ TritonX-100,2 $\mu \mathrm{g} / \mathrm{ml}$ leupeptin and $3 \mu \mathrm{g} / \mathrm{ml}$ aprotinin) and the protein concentrations were measured using a Bio-Rad Protein Assay kit (cat. no. 5000002; Bio-Rad Laboratories, Inc., Hercules, CA, USA). Proteins were separated by $10 \%$ SDS-PAGE and transferred to polyvinylidene difluoride membranes (Merck Millipore, Darmstadt, Germany). Subsequently, the membranes were blocked with $10 \%$ skimmed milk solution and then incubated overnight at $4^{\circ} \mathrm{C}$ with goat anti-EDD (cat. no. sc-9562), rabbit anti-B-cell lymphoma (Bcl)-2 (cat. no. sc-492), rabbit anti-Bcl-2-associated X protein (Bax; cat. no. sc-493), goat anti-caspase 3 p11 (cat. no. sc-1224) and goat anti-GAPDH (cat. no. sc-48166) polyclonal antibodies (1:2,000; all Santa Cruz Biotechnology, Inc., Dallas, TX, USA). Following washing with phosphate-buffered saline, the membranes were incubated with horseradish peroxidase-conjugated goat anti-rabbit $\operatorname{IgG}, \mathrm{F}\left(\mathrm{ab}^{\prime}\right)_{2}(1: 3,000$; cat. no. sc-3836) and chicken anti-goat IgG (1:3,000; cat. no. sc-516086; both Santa 
Cruz Biotechnology, Inc.) for $45 \mathrm{~min}$ at room temperature, prior to incubation with an enhanced chemiluminescence substrate (Thermo Fisher Scientific, Inc.). Subsequently, the membranes were visualized by exposure to ECL film and the band intensities were quantified using UN-SCAN-IT gel analysis software, version 5.1 (Silk Scientific, Inc., Orem, UT, USA). GAPDH was used as a reference gene.

Statistical analysis. All experiments were performed $\geq 3$ times. Data were presented as the mean \pm standard deviation, and were analyzed using SPSS 16.0 software (SPSS, Inc., Chicago, IL, USA). Statistical differences between two independent groups were determined using the unpaired Student's t-test. $\mathrm{P}<0.05$ was considered to indicate a statistically significant difference.

\section{Results}

EDD is overexpressed in cervical cancer tissue samples and cell lines. To investigate the role of EDD in cervical cancer, the expression levels of EDD were measured in cervical cancer tissue samples and cell lines using RT-qPCR and western blotting. EDD was significantly upregulated in the cervical cancer tissue samples at both the mRNA and protein levels $(\mathrm{P}<0.01$; Fig. 1A and B). Furthermore, the mRNA expression levels of EDD were significantly increased in the cervical cancer cell lines, as compared with the normal cervical epithelial cells $(\mathrm{P}<0.0001$; Fig. 1C). These results suggest that EDD is overexpressed in cervical cancer tissue samples and cell lines.

EDD promotes cervical cancer growth in vitro and in vivo. To further explore the role of abnormal EDD expression in cervical cancer, EDD expression was knocked down or upregulated in SiHa cells. EDD knockdown in SiHa cervical cancer cells significantly inhibited the growth of the cancer cells in vitro and in vivo. As shown in Fig. 2A and B, colony formation and cell proliferation were significantly inhibited in the SiHa cells when EDD was knocked-down in vitro. Furthermore, EDD silencing significantly suppressed the growth of cervical cancer tumors in vivo ( $\mathrm{P}<0.001$; Fig. $2 \mathrm{C}$ ). The opposite results were observed following EDD overexpression. EDD overexpression significantly increased colony formation, cell proliferation and tumor growth in cervical cancer $(\mathrm{P}<0.05$; Fig. 2D-F).

To investigate whether EDD regulates cervical cancer growth via an apoptotic mechanism, quantitative analysis of apoptotic cells was performed using fluorescence-activated cell sorting. The results demonstrated that EDD knockdown significantly increased the apoptosis of SiHa cells $(\mathrm{P}<0.001$; Fig. 3A), and reduced the protein expression levels of anti-apoptotic proteins, including Bcl-2, and increased the protein expression levels of pro-apoptotic proteins, including Bax and caspase 3 (Fig. 3B). These results suggest that EDD may have an oncogenic role in cervical cancer.

$E D D$ regulates the proliferation of cervical cancer cells via $m i R-143$. As previously demonstrated by Liu et al (56), miR-143 promotes apoptosis and inhibits tumor formation in cervical cancer. Therefore, it was hypothesized that EDD may regulate cervical cancer growth via miR-143. The expression levels of
miR-143 were analyzed in human cervical cancer tissue samples. The results demonstrated that miR-143 expression levels were significantly downregulated in cervical cancer tissue samples, as compared with the normal tissue samples ( $\mathrm{P}<0.001$; Fig. 4A).

Following this, the present study investigated whether the expression levels of miRNA-143 were correlated with EDD. EDD knockdown significantly increased miR-143 expression levels in SiHa cells ( $\mathrm{P}<0.001$; Fig. 4B), and miR-143 expression was negatively correlated with the expression levels of EDD in cervical cancer tissue samples ( $\mathrm{P}<0.001$; Fig. 4C), which suggests that EDD represses miR-143 expression in cervical cancer.

To further investigate whether miR-143 affected the function of EDD during the growth of cervical cancer, EDD and miR-143 were knocked-down and silenced respectively or simultaneously in SiHa cells. miR-143 sponge was used to eliminate miR-143 function. miR-143 silencing significantly reversed the inhibitory growth effect of EDD knockdown in SiHa cells $(\mathrm{P}<0.01$; Fig. 4D). Furthermore, miR-143 silencing eliminated the effect of EDD knockdown on colony formation and prevented the apoptosis induced by EDD knockdown in SiHa cells $(\mathrm{P}<0.01$; Fig. $4 \mathrm{E}$ and F). Therefore, these results demonstrate that EDD may regulate the proliferation of cervical cancer cells via miR-143.

\section{Discussion}

Previous studies have demonstrated that malignancies are frequently accompanied by the abnormal expression of oncogenes or tumor suppressor genes (59-65). EDD, as a human ortholog of the Drosophila melanogaster hyd gene (14), was shown to be frequently overexpressed in breast and ovarian cancer, which suggests that it may have a role in the progression of gynecological cancer $(31,33,36)$. Furthermore, Bradley et al (36) demonstrated that EDD downregulation decreased ovarian cancer cell viability, increased cell apoptosis, inhibited tumor growth and promoted platinum sensitivity through mediation of ubiquitin ligase activity. However, the function and molecular mechanisms of EDD in human cervical cancer have yet to be elucidated. The results of the present study demonstrated that EDD expression levels were significantly upregulated in cervical cancer cell lines and tissues. Functional studies showed that abnormal expression of EDD impacted cell proliferation and tumor growth in cervical cancer. Furthermore, EDD knockdown significantly inhibited colony formation, cell proliferation and tumor growth in vitro and in vivo via the activation of the apoptosis signal pathway. These results suggested that EDD may have an oncogenic role in human cervical cancer. Abnormal expression of EDD may result in the disorder of ubiquitination and deubiquitination via ubiquitin ligase E3 and mediate the aberrant expression of oncogenes or tumor suppressor genes, thus inducing tumor occurrence and development.

miRNAs are involved in a diverse range of biological processes (38-43) and previous studies have demonstrated that certain miRNAs may function as oncogenes or tumor suppressors, which are directly involved in cancer occurrence and development (44-53). cDNA cloning demonstrated that miR-143 is a tumor-suppressive miRNA in cervical cancer (52), and Liu et al (56) reported that miR-143 expression was 
downregulated in cervical cancer. The results of the present study demonstrated that miR-143 expression was downregulated in cervical cancer tissue samples. Furthermore, miR-143 expression levels were significantly increased following EDD knockdown and were negatively correlated with the expression of EDD, which suggested that miR-143 may be a functional target of EDD in cervical cancer. Subsequent functional investigation revealed that miR-143 silencing eliminated the effect of EDD knockdown on cell proliferation, colony formation and cell apoptosis in SiHa cells, indicating that miR-143 may be crucial for the function of EDD in regulating the growth of cervical cancer cells. These results are concordant with those of a previous study, which demonstrated that EDD regulates miRNA-mediated gene silencing and impacts the proliferation of cancer cells (27). Su et al (27) identified EDD as a key mediator for miRNA silencing via genetic screening in mouse embryonic stem cells. It was demonstrated that E3 ubiquitin ligase activity was dispensable for EDD function in miRNA silencing (27). However, the C-terminal domain of polyadenylate binding protein 1 (PABC) of EDD was demonstrated to be essential for its silencing function, as EDD regulated miRNA silencing via its PABC domain and PABC interactors (27). Furthermore, it has previously been demonstrated that miR-143 is able to promote cervical cancer cell apoptosis and inhibit tumor formation by targeting Bcl-2 (56). These findings, and the results of the present study, suggest that EDD may regulate miRNA-143 expression via its PABC domain which, in turn, impacts carcinogenesis and tumor growth.

In conclusion, the results of the present study demonstrated that EDD regulates cervical cancer growth in vivo and in vitro partly via miR-143. Furthermore, EDD may have an oncogenic role in cervical cancer and may be a potential target for cervical cancer therapy.

\section{Acknowledgements}

The present study was supported by grants from the Discipline Leaders Project of the Shanghai Municipal Pudong New Area Health System (grant no. PWRd2012-16) and the Key Discipline Funding Project of the Shanghai Municipal Pudong New Area Health Bureau (grant no. PWZx2014-09).

\section{References}

1. World Health Organization: Department of Reproductive Health and Research and Department of Chronic Diseases and Health Promotion: Comprehensive cervical cancer control: A guide to essential practice. World Health Organization, 2006.

2. World Health Organization: GLOBOCAN 2012: Estimated cancer incidence, mortality and prevalence worldwide in 2012. Lyon, France: International Agency for Research on Cancer, 2014.

3. Anorlu RI: Cervical cancer: The sub-Saharan African perspective. Reprod Health Matters 16: 41-49, 2008.

4. Rositch AF, Silver MI and Gravitt PE: Cervical cancer screening in older women: New evidence and knowledge gaps. PLoS Med 11: e1001586, 2014.

5. Noller K (ed): Intraepithelial neoplasia of the lower genital tract (cervix, vulva): Etiology, screening, diagnostic techniques, management. In: Comprehensive Gynecology. 5th edition. Mosby Elsevier, Philadelphia, PA, 2007.

6. Tewari KS, Sill MW, Long HJ III, Penson RT, Huang H, Ramondetta LM, Landrum LM, Oaknin A, Reid TJ, Leitao MM, et al: Improved survival with bevacizumab in advanced cervical cancer. N Engl J Med 370: 734-743, 2014.
7. Dizon DS, Mackay HJ, Thomas GM, Werner TL, Kohn EC, Hess D, Rose PG and Covens AL: State of the science in cervical cancer: Where we are today and where we need to go. Cancer 120: 2282-2288, 2014

8. Maguire R, Kotronoulas G, Simpson M and Paterson C: A systematic review of the supportive care needs of women living with and beyond cervical cancer. Gynecol Oncol 136: 478-490, 2015.

9. Schiffman M, Castle PE, Jeronimo J, Rodriguez AC and Wacholder S: Human papillomavirus and cervical cancer. Lancet 370: 890-907, 2007.

10. Chaturvedi AK: Beyond cervical cancer: Burden of other HPV-related cancers among men and women. J Adolesc Health 46 (Suppl): S20-S26, 2010.

11. Burd EM: Human papillomavirus and cervical cancer. Clin Microbiol Rev 16: 1-17, 2003.

12. Dasari S, Wudayagiri R and Valluru L: Cervical cancer: Biomarkers for diagnosis and treatment. Clin Chim Acta 445: 7-11, 2015.

13. Tasaki T, Mulder LC, Iwamatsu A, Lee MJ, Davydov IV, Varshavsky A, Muesing M and Kwon YT: A family of mammalian E3 ubiquitin ligases that contain the UBR box motif and recognize N-degrons. Mol Cell Biol 25: 7120-7136, 2005.

14. Callaghan MJ, Russell AJ, Woollatt E, Sutherland GR, Sutherland RL and Watts CK: Identification of a human HECT family protein with homology to the Drosophila tumor suppressor gene hyperplastic discs. Oncogene 17: 3479-3491, 1998.

15. Henderson MJ, Russell AJ, Hird S, Muñoz M, Clancy JL, Lehrbach GM, Calanni ST, Jans DA, Sutherland RL and Watts CK: EDD, the human hyperplastic discs protein, has a role in progesterone receptor coactivation and potential involvement in DNA damage response. J Biol Chem 277: 26468-26478, 2002.

16. Beaudenon SL, Huacani MR, Wang G, McDonnell DP and Huibregtse JM: Rsp5 ubiquitin-protein ligase mediates DNA damage-induced degradation of the large subunit of RNA polymerase II in Saccharomyces cerevisiae. Mol Cell Biol 19: 6972-6979, 1999

17. Kornitzer D and Ciechanover A: Modes of regulation of ubiquitin-mediated protein degradation. J Cell Physiol 182: 1-11, 2000

18. Connor MK and Seth A: A central role for the ring finger protein RNF11 in ubiquitin-mediated proteolysis via interactions with E2s and E3s. Oncogene 23: 2089-2095, 2004.

19. Ang XL and Wade Harper J: SCF-mediated protein degradation and cell cycle control. Oncogene 24: 2860-2870, 2005.

20. Vidhyasekaran P (ed): Ubiquitin-proteasome system-mediated protein degradation in defense signaling. In: PAMP Signals in Plant Innate Immunity. Springer, The Netherlands, pp409-430, 2014.

21. Benavides M, Chow-Tsang LF, Zhang J and Zhong H: The novel interaction between microspherule protein Msp58 and ubiquitin E3 ligase EDD regulates cell cycle progression. Biochim Biophys Acta 1833: 21-32, 2013.

22. Ling S and Lin WC: EDD inhibits ATM-mediated phosphorylation of p53. J Biol Chem 286: 14972-14982, 2011.

23. Munoz MA, Saunders DN, Henderson MJ, Clancy JL, Russell AJ, Lehrbach G, Musgrove EA, Watts CK and Sutherland RL: The E3 ubiquitin ligase EDD regulates S-phase and G2/M DNA damage checkpoints. Cell Cycle 6: 3070-3077, 2007.

24. Smits VA: EDD induces cell cycle arrest by increasing p53 levels. Cell Cycle 11: 715-720, 2012.

25. McDonald WJ, Thomas LN, Koirala $\mathrm{S}$ and Too CK: Progestin-inducible EDD E3 ubiquitin ligase binds to $\alpha 4$ phosphoprotein to regulate ubiquitination and degradation of protein phosphatase PP2Ac. Mol Cell Endocrinol 382: 254-261, 2014.

26. Chen HW, Yang CC, Hsieh CL, Liu H, Lee SC and Tan BC: A functional genomic approach reveals the transcriptional role of EDD in the expression and function of angiogenesis regulator ACVRL1. Biochim Biophys Acta 1829: 1309-1319, 2013.

27. Su H, Meng S, Lu Y, Trombly MI, Chen J, Lin C, Turk A and Wang X: Mammalian hyperplastic discs homolog EDD regulates miRNA-mediated gene silencing. Mol Cell 43: 97-109, 2011.

28. Bethard JR, Zheng H, Roberts L and Eblen ST: Identification of phosphorylation sites on the E3 ubiquitin ligase UBR5/EDD. J Proteomics 75: 603-609, 2011.

29. Henderson MJ, Munoz MA, Saunders DN, Clancy JL, Russell AJ, Williams B, Pappin D, Khanna KK, Jackson SP, Sutherland RL and Watts CK: EDD mediates DNA damage-induced activation of CHK2. J Biol Chem 281: 39990-40000, 2006.

30. Gwinn D and Sweet-Cordero EA: The phosphatase PP2A links glutamine to the tumor suppressor p53. Mol Cell 50: 157-158, 2013. 
31. Clancy JL, Henderson MJ, Russell AJ, Anderson DW, Bova RJ, Campbell IG, Choong DY, Macdonald GA, Mann GJ, Nolan T, et al: EDD, the human orthologue of the hyperplastic discs tumour suppressor gene, is amplified and overexpressed in cancer. Oncogene 22: 5070-5081, 2003.

32. Fuja TJ, Lin F, Osann KE and Bryant PJ: Somatic mutations and altered expression of the candidate tumor suppressors CSNK1E, DLG1, and EDD/hHYD in mammary ductal carcinoma. Cancer Res 64: 942-951, 2004.

33. O'Brien PM, Davies MJ, Scurry JP, Smith AN, Barton CA, Henderson MJ, Saunders DN, Gloss BS, Patterson KI, Clancy JL et al: The E3 ubiquitin ligase EDD is an adverse prognostic factor for serous epithelial ovarian cancer and modulates cisplatin resistance in vitro. Br J Cancer 98: 1085-1093, 2008.

34. Kruzelock RP and Short W: Colorectal cancer therapeutics and the challenges of applied pharmacogenomics. Curr Probl Cancer 31: 315-366, 2007.

35. Yoon SY, Lee Y, Kim JH, Chung AS, Joo JH, Kim CN, Kim NS, Choe IS and Kim JW: Over-expression of human UREB1 in colorectal cancer: HECT domain of human UREB1 inhibits the activity of tumor suppressor p53 protein. Biochem Biophys Res Commun 326: 7-17, 2005.

36. Bradley A, Zheng H, Ziebarth A, Sakati W, Branham-O'Connor M, Blumer JB, Liu Y, Kistner-Griffin E, Rodriguez-Aguayo C, Lopez-Berestein G, et al: EDD enhances cell survival and cisplatin resistance and is a therapeutic target for epithelial ovarian cancer. Carcinogenesis 35: 1100-1109, 2014.

37. Bartel DP: MicroRNAs: Genomics, biogenesis, mechanism, and function. Cell 116: 281-297, 2004.

38. Bueno MJ, Pérez de Castro I and Malumbres M: Control of cell proliferation pathways by microRNAs. Cell Cycle 7: 3143-3148, 2008

39. Conrad R, Barrier M and Ford LP: Role of miRNA and miRNA processing factors in development and disease. Birth Defects Res C Embryo Today 78: 107-117, 2006.

40. Schoolmeesters A, Eklund T, Leake D, Vermeulen A, Smith Q, Force Aldred S and Fedorov Y: Functional profiling reveals critical role for miRNA in differentiation of human mesenchymal stem cells. PLoS One 4: e5605, 2009.

41. Shantikumar S, Caporali A and Emanueli C: Role of miRNA in diabetes and its cardiovascular complications. Cardiovasc Res 93 583-93, 2012.

42. Wang Y, Zhang X, Li H, Yu J and Ren X: The role of miRNA-29 family in cancer. Eur J Cell Biol 92: 123-128, 2013.

43. Williams AE, Perry MM, Moschos SA, Larner-Svensson HM and Lindsay MA: Role of miRNA-146a in the regulation of the innate immune response and cancer. Biochem Soc Trans 36 : 1211-1215, 2008.

44. Zhang N, Su Y and Xu L: Targeting PKCe by miR-143 regulates cell apoptosis in lung cancer. FEBS Lett 587: 3661-3667, 2013.

45. Zhang B, Pan X, Cobb GP and Anderson TA: microRNAs as oncogenes and tumor suppressors. Dev Biol 302: 1-12, 2007.

46. Pham H, Rodriguez CE, Donald GW, Hertzer KM, Jung XS Chang HH, Moro A, Reber HA, Hines OJ and Eibl G: miR-143 decreases COX-2 mRNA stability and expression in pancreatic cancer cells. Biochem Biophys Res Commun 439: 6-11, 2013

47. Zhang X, Dong Y, Ti H, Zhao J, Wang Y, Li T and Zhang B: Down-regulation of miR-145 and miR-143 might be associated with DNA methyltransferase 3B overexpression and worse prognosis in endometrioid carcinomas. Hum Pathol 44: 2571-2580, 2013.

48. Wang LQ, Zhang Y, Yan H, Liu KJ and Zhang S: MicroRNA-373 functions as an oncogene and targets YOD1 gene in cervical cancer. Biochem Biophys Res Commun 459: 515-520, 2015.
49. Puerta-Gil P, García-Baquero R, Jia AY, Ocaña $S$, Alvarez-Múgica M, Alvarez-Ossorio JL, Cordon-Cardo C, Cava F and Sánchez-Carbayo M: miR-143, miR-222, and miR-452 are useful as tumor stratification and noninvasive diagnostic biomarkers for bladder cancer. Am J Pathol 180: 1808-1815, 2012.

50. Zhu H, Dougherty U, Joseph LJ, Robinson V, Wu J, Song Z, Mustaf R, Fichera A and Bissonnette M: 1068 EGFR and c-MYC suppress Mir-143 and Mir-145 in colonic tumorigenesis: Roles of G1 cell cycle regulators as miRNA targets. Gastroenterol 136: A164-A165, 2009.

51. Cho WC: MicroRNAs in cancer - from research to therapy. Biochim Biophys Acta 1805: 209-217, 2010.

52. Wang X, Tang S, Le SY, Lu R, Rader JS, Meyers C and Zheng ZM Aberrant expression of oncogenic and tumor-suppressive microRNAs in cervical cancer is required for cancer cell growth. PLoS One 3: e2557, 2008.

53. Tang T, Wong HK, Gu W, Yu MY, To KF, Wang CC, Wong YF, Cheung TH, Chung TK and Choy KW: MicroRNA-182 plays an onco-miRNA role in cervical cancer. Gynecol Oncol 129: 199-208, 2013.

54. Qian X, Yu J, Yin Y, He J, Wang L, Li Q, Zhang LQ, Li CY, Shi ZM, Xu Q, et al: MicroRNA-143 inhibits tumor growth and angiogenesis and sensitizes chemosensitivity to oxaliplatin in colorectal cancers. Cell Cycle 12: 1385-1394, 2013.

55. Shepherd JH: Cervical and vulva cancer: changes in FIGO definitions of staging. Br J Obstet Gynaecol 103: 405-406, 1996.

56. Liu L, Yu X, Guo X, Tian Z, Su M, Long Y, Huang C, Zhou F, Liu M, Wu X and Wang X: miR-143 is downregulated in cervical cancer and promotes apoptosis and inhibits tumor formation by targeting Bcl-2. Mol Med Rep 5: 753-760, 2012.

57. Hu CE, Liu YC, Zhang HD and Huang GJ: The RNA-binding protein PCBP2 facilitates gastric carcinoma growth by targeting miR-34a. Biochem Biophys Res Commun 448: 437-442, 2014.

58. Livak KJ and Schmittgen TD: Analysis of relative gene expression data using real-time quantitative PCR and the $2-\Delta \Delta \mathrm{Ct}$ method. Methods 25: 402-408, 2001

59. Guo G, Kang Q, Chen Q, Chen Z, Wang J, Tan L and Chen JL: High expression of long non-coding RNA H19 is required for efficient tumorigenesis induced by Bcr-Abl oncogene. FEBS 588 1780-1786, 2014

60. Kennedy AL, Morton JP, Manoharan I, Nelson DM, Jamieson NB, Pawlikowski JS, McBryan T, Doyle B, McKay C, Oien KA, et al: Activation of the PIK3CA/AKT pathway suppresses senescence induced by an activated RAS oncogene to promote tumorigenesis. Mol Cell 42: 36-49, 2011.

61. Sala A, Bettuzzi S, Pucci S, Chayka O, Dews $M$ and Thomas-Tikhonenko A: Regulation of CLU gene expression by oncogenes and epigenetic factors: Implications for tumorigenesis. Adv Cancer Res 105: 115-132, 2009.

62. Keyes WM, Pecoraro M, Aranda V, Vernersson-Lindahl E, Li W, Vogel H, Guo X, Garcia EL, Michurina TV, Enikolopov G, et al: $\Delta \mathrm{Np} 63 \alpha$ is an oncogene that targets chromatin remodeler Lsh to drive skin stem cell proliferation and tumorigenesis. Cell Stem Cell 8: 164-176, 2011.

63. Couto SS, Cao M, Duarte PC, Banach-Petrosky W, Wang S, Romanienko P, Wu H, Cardiff RD, Abate-Shen C and Cunha GR: Simultaneous haploinsufficiency of Pten and Trp53 tumor suppressor genes accelerates tumorigenesis in a mouse model of prostate cancer. Differentiation 77: 103-111, 2009.

64. Imanishi $\mathrm{Y}$ and Tahara $\mathrm{H}$ : Putative parathyroid tumor suppressor on 1p: Independent molecular mechanisms of tumorigenesis from 11q allelic loss. Am J Kidney Dis 38 (Suppl 1): S165-S167, 2001.

65. Mercier PL, Bachvarova M, Plante M, Gregoire J, Renaud MC, Ghani K, Têtu B, Bairati I and Bachvarov D: Characterization of DOK1, a candidate tumor suppressor gene, in epithelial ovarian cancer. Mol Oncol 5: 438-453, 2011. 